\title{
Comparison of nitrogenase and nitrate reductase activities in two nitrogen-fixing tree species: black alder (Alnus glutinosa) and black locust (Robinia pseudoacacia)
}

\author{
G. Pizelle ${ }^{1}$, S. Benamar ${ }^{1}$, F. Boutekrabt ${ }^{1}$ and G. Thiéry ${ }^{2}$ \\ 1 Laboratoire de Physiologie Végétale et Forestière, Faculté des Sciences, BP 239, 54506 \\ Vandoeuvre-lès-Nancy Cedex, and \\ 2 Physiologie Végétale, ENSAIA, 54500 Vandœuvre-lès-Nancy, France
}

\section{Introduction}

Among the symbiotic nitrogen-fixing trees of the temperate zone, black alder (Alnus glutinosa, L. Gaertn.) and black locust (Robinia pseudoacacia L.) can be regarded as typical actinorhizal (frankial) and leguminous (rhizobial) woody species, respectively. Important differences between both species concern their biological, ecological and symbiotic characteristics, and the greater amount of work recently devoted to $A$. glutinosa, which likely prevails over $R$. pseudoacacia on the following grounds: ubiquity in Europe, better sylvicultural qualities, absence of spines and suckers, easier collection of the nitrogen-fixing organs, attraction to the more recently recognized actinorhizal symbiosis (Tjepkema et al., 1986). Nevertheless, $R$. pseudoacacia is also a tree of interest both for its role as symbiont in nitrogen fixation and for its potential value as timber and wood fiber source (Moiroud and Capellano, 1982; Turvey and Smeth- urst, 1983); hence, our desire to progress in understanding of its physiology.

In an extension of our work on nitrogen nutrition of $A$. glutinosa (e.g., Pizelle and Thiéry, 1986), the present paper examines the nitrogenase and nitrate reductase activities, measured in vivo, in R. pseudoacacia and compares them with the data from A. glutinosa.

\section{Materials and Methods}

Plant material was harvested in the early afternoon from 15-20 yr old black alders naturally growing on sandy alluvium and from black locusts planted for about $10 \mathrm{yr}$ on a sandy and stony bank; both sites were located on a siliceous substrate in the Moselle valley near Nancy.

Nitrogenase $\left(\mathrm{N}_{2}\right.$ ase) activity was assayed by the $\mathrm{C}_{2} \mathrm{H}_{2}$ reduction method on excised actinorhizal lobes of alder and on excised nodules of black locust. Nitrate reductase (NR) activities were assayed on $5 \mathrm{~mm}$ sections of small roots (diameter $\leq 1 \mathrm{~mm} ; 100 \mathrm{mg}$ fresh tissue) and on disks of young fully expanded leaves (diameter: 
$12 \mathrm{~mm} ; 2$ disks). The root samples were vacuum infiltrated in $2.5 \mathrm{ml}$ of $0.1 \mathrm{M}$ NaK phosphate buffer, $\mathrm{pH} 7.5$, with or without $0.05 \mathrm{M}$ $\mathrm{KNO}_{3}$. After incubation for $1 \mathrm{~h}$ at $30^{\circ} \mathrm{C}$ in the dark, $1.5 \mathrm{ml}$ of incubation medium were cleared by addition of $0.3 \mathrm{ml}$ of $1 \mathrm{M} \mathrm{Zn}$ acetate and centrifugation. In the leaf NR assays, Triton $X-100$ was added $(0.1 \%, v / v)$ to the incubation medium and clearance of $\mathrm{Zn}$ acetate was not necessary. The nitrite concentrations of the NR incubation media and soil nitrate content were determined as described by Pizelle and Thiéry (1986).

\section{Results}

$N_{2}$ ase activity

In $A$. glutinosa the enzyme activity started earlier in spring and disappeared later in autumn than in $R$. pseudoacacia. During the growing season, $\mathrm{N}_{2}$ ase activity of the nodules of $R$. pseudoacacia reached higher values than that of the actinorhizas of $A$. glutinosa (Fig. 1). This difference might be explained by the following characteristics: most nodules of black locust were less than $1 \mathrm{yr}$ old with a large volume of inner tissues invaded by the active bacteroids, whereas the alder actinorhizas included lobes of various ages (often more than $1 \mathrm{yr}$ old) with the tissues containing the active vesicles of Frankia limited to the subapical cortical region.

NR activity of the small roots

Root NR activity of both species did not disappear in winter (Fig. 2). The enzyme

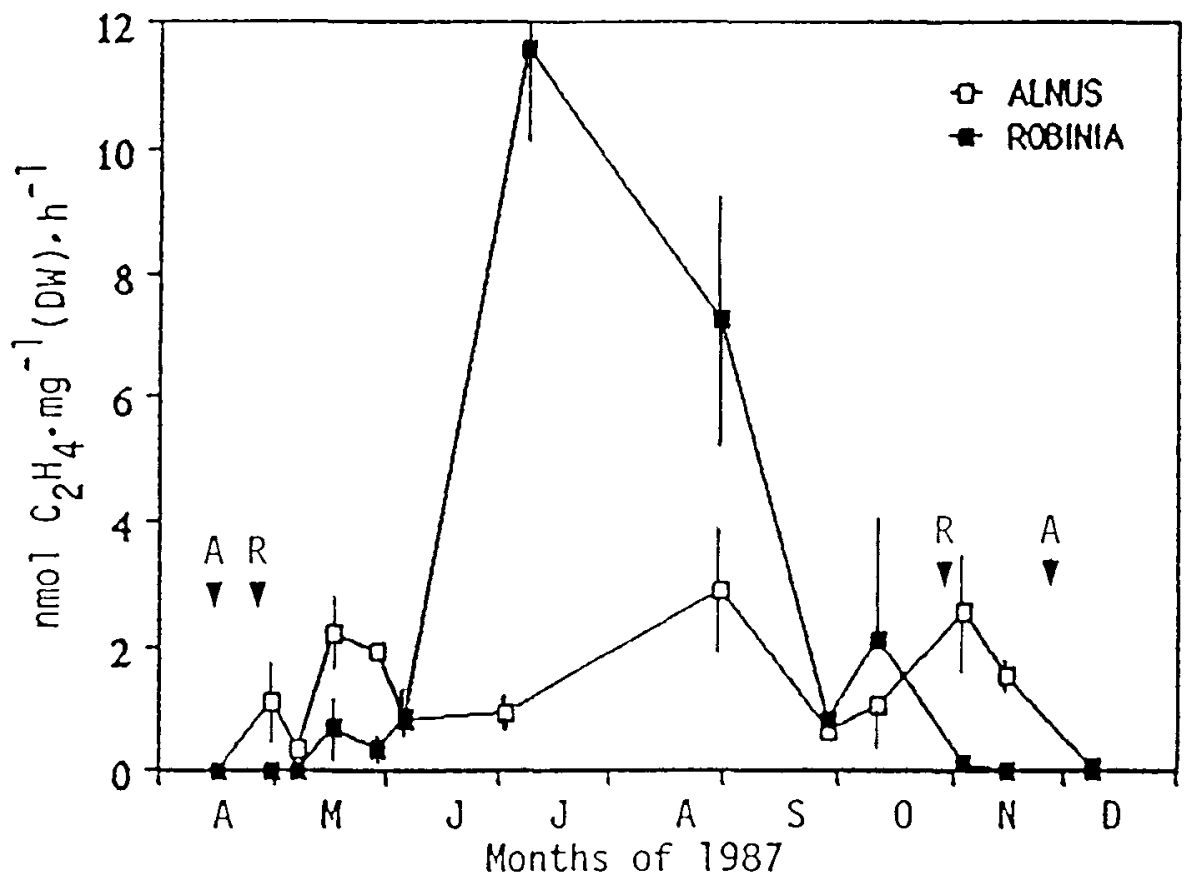

Fig. 1. Seasonal variations of the nitrogenase activity in actinorhizas of $A$. glutinosa (A) and nodules of $R$. pseudoacacia (R). Means of 3 replicates $\pm S E$ (when size of $S E>$ size of symbol). Arrowheads indicate the dates of bud opening (left) and of leaf fall (right). 
activity and the soil nitrate content of the relevant site showed higher values in $A$. glutinosa than in $R$. pseudoacacia. In contrast with the alder roots, the roots of black locust likely accumulated nitrate, since the NR activities measured with and without $\mathrm{KNO}_{3}$ in the incubation medium were similar.

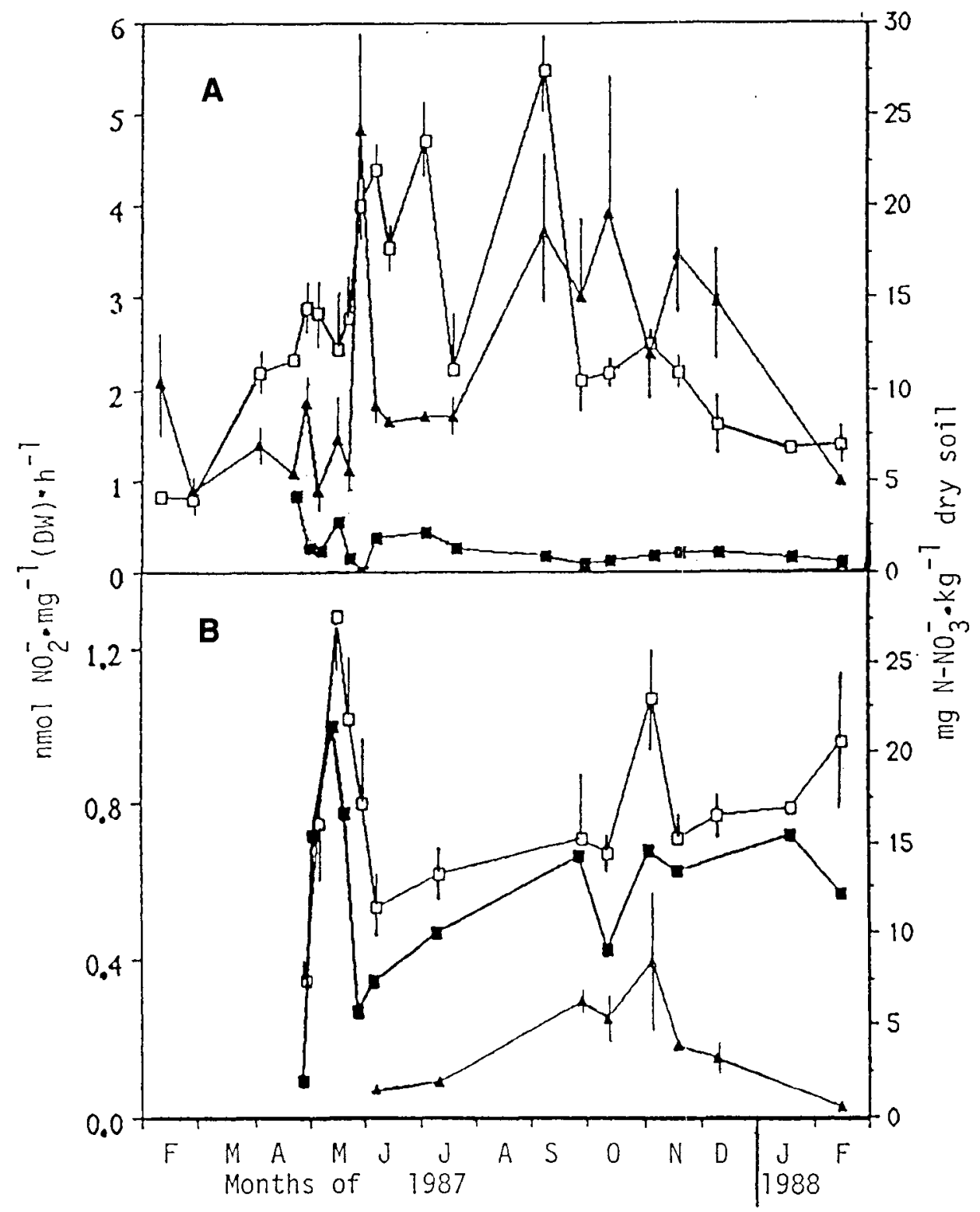

Fig. 2. Seasonal variations of the soil nitrate content $(\mathbf{\Delta})$ and root nitrate reductase activity measured with $(\square)$ and without (ם) $0.05 \mathrm{M} \mathrm{KNO}_{3}$ in the incubation medium. A. A. glutinosa. B. R. pseudoacacia. $\mathbf{\Delta}$ and $\square$ : means of 3 replicates $\pm S E$ (when size of $S E>$ size of symbol); $\boldsymbol{C}$ : one measurement on the fooled root samples. 
At the $A$. glutinosa site, higher values of soil nitrate content and of enzyme activity were measured during the growing season, but no significant correlation ( $r=$ $0.25 ; n=21$ ) was found between these parameters.

\section{NR activity of the leaves}

Previous experiments showed that the leaf NR activity of field-grown $A$. glutinosa was high after bud opening in the spring, then decreased during the growing season, before disappearing at the leaf fall; the presence of this NR activity was found to be independent of the supply of nitrate to the leaves via the xylem sap (Pizelle and Thiéry, 1977; 1986).

From the present data (Table 1), it appears that field-grown $R$. pseudoacacia also had a notable leaf NR activity; the values were lower in spring than in summer, unlike the pattern observed in A. glutinosa. It is presently unknown whether the variations of the leaf enzyme activity were controlled by the nitrate supply under field conditions. However, assays using young nodulated black locusts grown on nutrient solution without nitrate showed an increase of their leaf NR activity from $0.78 \pm 0.16$ to $3.23 \pm 1.15 \mathrm{nmol} \mathrm{NO}-\cdot \mathrm{mg}^{-1}$ $\mathrm{DW} \cdot \mathrm{h}^{-1}$ (means of 4 samples $\pm \mathrm{SE}$ ) after 3 days of $4 \mathrm{mM} \mathrm{NaNO}_{3}$ supply.

\section{Discussion and Conclusion}

Though the age of the trees and the nature or nitrate content of the soil differed between the respective sites of each species, the present data reveal some characteristics of the in vivo $\mathrm{N}_{2}$ ase and $\mathrm{NR}$ activities in field-grown $A$. glutinosa and R. pseudoacacia.

$\mathrm{N}_{2}$ ase activity of the actinorhizas of $A$. glutinosa lasted longer but reached lower values than that of the nodules of $R$. pseudoacacia during the growing season. These differences are probably related to the length of the period of active photosynthesis and to the anatomical structure of the nitrogen-fixing organs in each species. Since $\mathrm{N}_{2}$ ase activity is measured per $\mathrm{mg}$ dry weight of actinorhiza or nodule, further data, such as the mass of symbiotic organs per tree, would be necessary to compare the nitrogen-fixing potential of the trees of both species.

The presence of a root NR activity in winter indicates the persistence of the enzyme and reducing power in the roots out of the growing season. Since nitrate was found in the soil, even in winter, it might suffice to maintain a nitrate-inducible NR activity in the roots throughout the year. The presence of non-reduced nitrate in the roots of $R$. pseudoacacia, in spite of a low nitrate content in the soil, indicates a limited root NR activity in this

Table I. Seasonal variations of the leaf nitrate reductase activity $\left(\mathrm{nmol} \mathrm{NO} \mathrm{N}_{2}^{-\cdot} \cdot \mathrm{mg}^{-1} \mathrm{DW} \cdot \mathrm{h}^{-1}\right)$ in $\mathrm{A} . \mathrm{glu}-$ tinosa and $R$. pseudoacacia.

\begin{tabular}{lccrrrr}
\hline Species & Dates & & & & \\
\cline { 2 - 6 } & $1 / 5 / 87$ & $15 / 5 / 87$ & $4 / 588$ & $9 / 5 / 88$ & $7 / 7 / 88$ & \multicolumn{1}{c}{$30 / 8 / 88$} \\
\hline A. glutinosa & 5.76 & - & 6.49 & 5.35 & 1.88 & 3.36 \\
& \pm 0.63 & & \pm 0.91 & \pm 0.34 & \pm 0.34 & \pm 0.78 \\
R. pseudoacacia & - & 0.83 & - & 0.82 & 2.22 & 1.37 \\
& & \pm 0.28 & & \pm 0.24 & \pm 0.54 & \pm 0.69 \\
\hline
\end{tabular}

Mean of 3 replicates \pm SE. 
species. In $A$. glutinosa, the negligible accumulation of nitrate in the roots and the absence of a close correlation between root NR activity and soil nitrate content suggest that the roots have an NR capacity able to reduce higher amounts of nitrate than those available in the soil.

The seasonal profile of the leaf NR activity of $A$. glutinosa appears to be independent of the nitrate supply; it decreases from the early leaf expansion to the approach of the leaf fall. In $R$. pseudoacacia the leaf NR activity shows a different profile with values lower in spring and higher in summer. Given the results obtained from young laboratory-grown plants as well as the presence of a limited nitrate-reducing capacity of the roots, it can be proposed that the leaves of $R$. pseudoacacia have an NR activity commensurate with their supply of nitrate.

\section{References}

Moiroud A. \& Capellano A. (1982) Le robinier, Robinia pseudoacacia L., une espece fixatrice d'azole intéressante ? Ann. Sci. For. 39, 407418

Pizelle G. \& Thiéry G. (1977) Variations saisonnières des activités nitrogénase et nitrate réductase chez l'aune glutineux (Alnus glutinosa L. Gaertn.). Physiol. Vég. 15, 333-342

Pizelle G. \& Thiery G. (1986) Reduction of nitrate in the perennial tissues of aerial parts of Alnus glutinosa. Physiol. Plant. 68, 347-352

Tjepkema J.D., Schwintzer C.R. \& Benson D.R. (1986) Physiology of actinorhizal nodules. Annu. Rev. Plant Physiol. 37, 209-232

Turvey N.D. \& Smethurst P.J. (1983) Nitrogen fixing plants in forest plantation. In: Biological Nitrogen Fixation in Forest Ecosystems: Foundations and Applications. (Gordon J.C. \& Wheeler C.T., eds.), Martinus Nijhoff, The Hague, pp. 233-260 